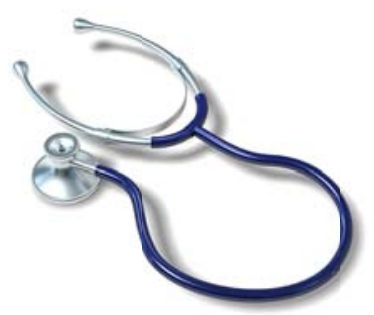

\title{
CLINICAL QUIZ
}

\section{Evaluation of a Submucosal Gastric Lesion}

\author{
Karim R. Masri, M.D. \\ William J. Salyers, M.D. \\ KU School of Medicine-Wichita \\ Department of Internal Medicine \\ Wichita, KS
}

A 25-year-old black female presented to the gastroenterology clinic for evaluation of a submucosal gastric lesion. She had a computed tomography (CT) performed for evaluation of right lower quadrant pain and had a low density, well circumscribed, mildly exophytic appearing intramural lesion in the distal antrum along the greater curvature of the stomach measuring 2.6 $\mathrm{cm} \quad \mathrm{x} \quad 2 \mathrm{~cm} \quad \mathrm{x} 2.2 \mathrm{~cm}$ (Figure 1). Esophagogastroduodenoscopy (EGD) revealed an extrinsic/subepithelial lesion (Figure 2) at the junction of the gastric body and antrum. She had no other complaints and denied gastrointestinal bleeding. She underwent an endoscopic ultrasound that showed a 3.01-cm x 1.35-cm cyst arising from the deep mucosal layer of the gastric antrum without involvement of the muscularis propria. Fine-needle aspiration drainage of a total of $8.5 \mathrm{~mL}$ of clear fluid was performed successfully. Additional sub-centimeter small cystic area within the submucosa adjacent to this cystic lesion was identified but was not accessed separately due to its small size (Figure 3). Cytology of fluid was nonmalignant. Carcinoembryonic antigen could not be performed due to viscosity of fluid. Fluid amylase was 433.

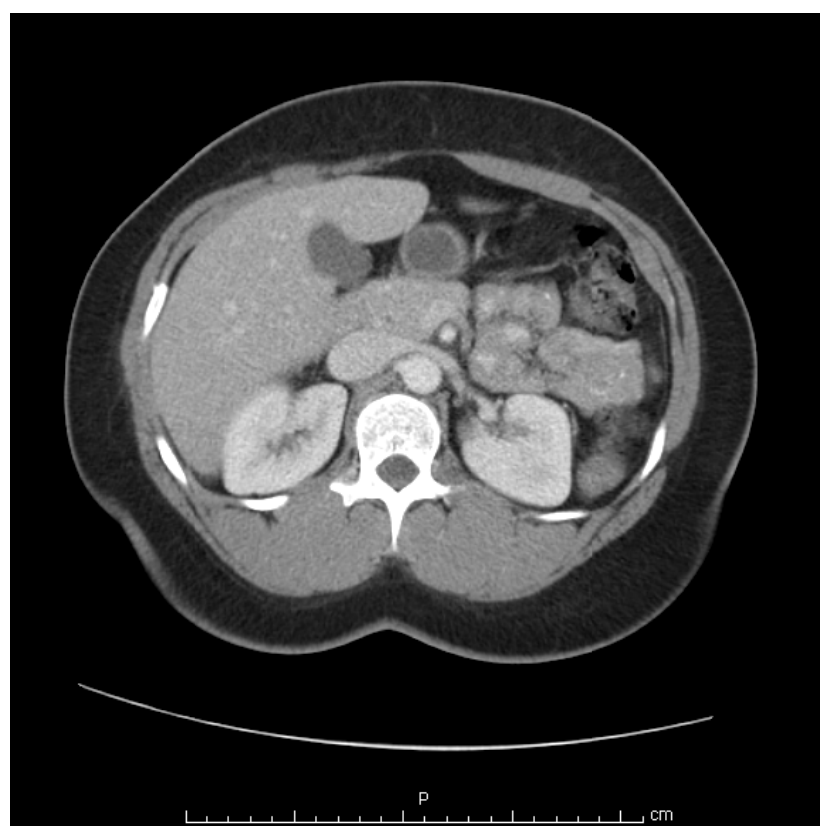

Figure 1. CT section of suspicious lesion. 


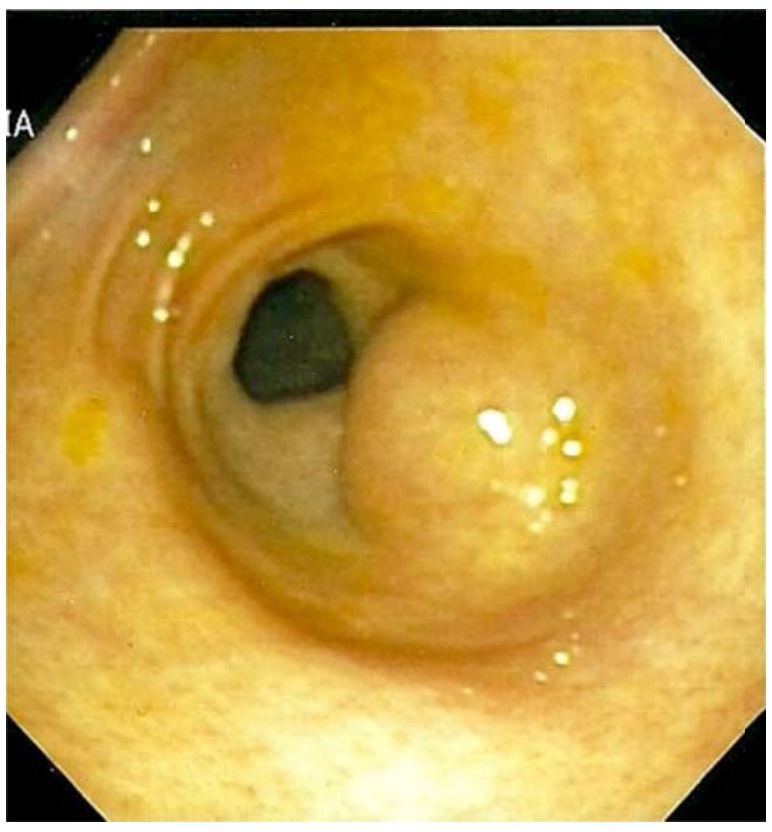

Figure 2. EGD of suspicious lesion.

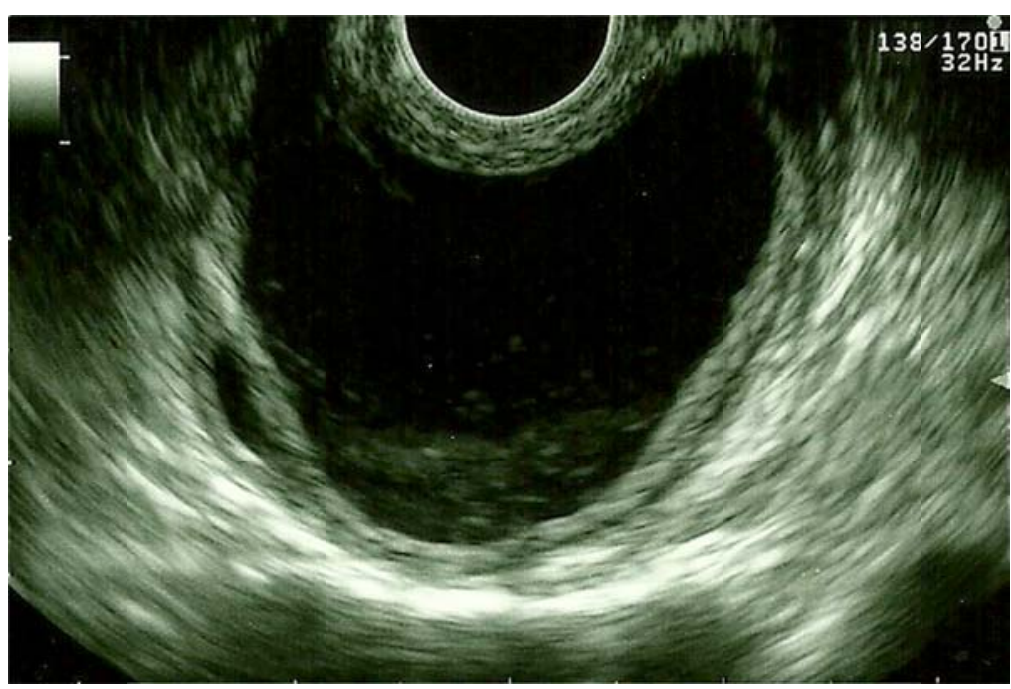

Figure 3. Endoscopic ultrasound of suspicion lesion.

What is the most likely diagnosis?
A. Carcinoid
B. Choledochal Cyst
C. Gastric Carcinoma
D. Gastric Duplication Cyst
E. Gastrointestinal Stromal Tumor (GIST)
F. Pancreatic Pseudocyst
G. Zollinger-Ellison Tumor (Gastrinoma) 


\section{Correct Answer: D. Gastric Duplication Cyst}

Gastric duplication cysts are rare congenital anomalies that form during early embryonic development. They are usually seen in the proximal gastrointestinal tract, most commonly in the proximal small bowel, stomach and esophagus. They may be communicating with the lumen or adjacent without luminal communication. ${ }^{1,2}$ They usually are identified during endoscopic ultrasound or CT imaging. They usually are asymptomatic, but rarely, may manifest as dysphagia, abdominal pain, and acute pancreatitis if near the ampulla of Vater. ${ }^{3}$ They are low risk for malignancy. ${ }^{4}$

\section{References}

1. Geller A, Wang KK, DiMagno EP. Diagnosis of foregut duplication cysts by endoscopic ultrasonography. Gastroenterology 1995; 109(3):838-842. PMID 7657112.

2. Woolfolk GM, McClave SA, Jones WF, Oukrop RB, Mark MD. Use of endoscopic ultrasound to guide the diagnosis and endoscopic management of a large gastric duplication cyst. Gastrointest Endosc 1998; 47(1):76-79. PMID 9468429.

3. Faigel DO, Burke A, Ginsberg GG, Stotland BR, Kadish SL, Kochman ML. The role of endoscopic ultrasound in the evaluation and management of foregut duplications. Gastrointest Endosc 1997; 45(1):99-103. PMID 9013183.

4. Coit DG, Mies C. Adenocarcinoma arising within a gastric duplication cyst. J Surg Oncol 1992; 50(4):274-277. PMID 1640716.

Keywords: gastrointestinal diseases, congenital abnormalities, cysts, endoscopic ultrasonography 